\title{
Experimental Investigation of Mineral Composite Bonder over CFRP and GFRP Retrofits
}

\author{
Raghavendra Vasudeva Upadhyaya \\ Research Scholar: Engineering and Technology \\ Central Queensland University \\ Rockhampton, QLD, Australia
}

\author{
T. G. Suntharavadivel \\ Lecturer: Engineering and Technology \\ Central Queensland University \\ Rockhampton, QLD, Australia
}

\begin{abstract}
The importance in rehabilitation of concrete structures is rapidly gaining popularity due to various factors. In recent years, the Fiber Reinforced Polymer (FRP) is being widely applied in structural strengthening and retrofit. In most of the FRP strengthening the epoxy resin is used as a binder. A sustainable Mineral Based Composite (MBC) was tested to be a potential replacement for the epoxy in the FRP retrofit to overcome the drawbacks associated with epoxies. FRP sheets would be used to wrap around the damaged concrete surface with the help of innovative mineral bonders. The experimental results indicate the proposed $\mathrm{MBC}$ bonder have comparable behavior in FRP retrofit as epoxy.
\end{abstract}

Keywords- Epoxy; MBC; bonders; FRP retrofit; strengthening; debonding

\section{INTRODUCTION}

The infrastructural demand around the world is increasing day-by-day which is least concerned about the multidisciplinary aspects such as energy, economy and environment (EEE's). Concrete deterioration occurs due to various natural and induced phenomena resulting in global concern. The infrastructural deficiencies need immediate attention as it directly affects the operational life of the structure. The main objective of this research is to develop and implement a suitable eco-friendly bonding agent in order to eliminate the hazardous chemical resins used commercially. Fiber reinforced Polymer strengthening is a commonly practised rehabilitation technique which enhances the loadbearing capacity of the overall structure. The important issue to be addressed here is that FRP retrofit uses epoxy as a bonding agent which has been identified to cause adverse health impacts and is very toxic. A lot of published literature proves this fact. This paper aims to retrofit bi-directionally woven CFRP and GFRP materials around the damaged structural samples and extensively compare their bonding performance with that of epoxy resin and the newly developed mineral-based binder. The test specimens were subjected to various damage levels and experimented their bonding efficiency under tensile and compressive loads. The MBC material was developed after undertaking extensive literature study and implementing various rheology constraint materials and water reducing agents. After a series of trial and error, the durability and ease of availability of materials resulted in developing the final mix proportion of the sustainable composite as discussed in the paper

\section{LITERATURE INVESTIGATION}

\section{A. Epoxy and its associated concerns}

Although epoxy resins are considered as the most important composite in industrial and construction activities, it allows for some demerits to add to its list. First of all, it is highly volatile and vulnerable to freeze-thaw conditions as well as extreme temperatures. Secondly, it has adverse health impacts on the people working or living with them as it fumes out toxic gases if the temperature goes above $82^{\circ} \mathrm{C}$. Moreover, it cannot be applied on humid conditions. The health hazards investigation as per [1] exhibited by various plastics, which constitute a global production of 245 million tons annually in 2008 and shockingly doubled over the last 15 years. The most hazardous ranking of polymers falls under category $1 \mathrm{~A}$ or $1 \mathrm{~B}$ with examples of polyurethanes, polyvinyl chlorides, epoxy resins, and styrenic copolymers. On the other hand, [2] seemed to have conducted a patch test research on the population of North-Eastern Italy in order to investigate the effect of epoxy resins in contact with dermatitis (upper layer of the skin). It was observed that the sensitization on the human skin was $40.25 \%$. In both sexes of woodworkers, chemical industry or construction workers, farmers and fishers, significant health effects were found due to working with epoxy resins. The study conducted by [3] established that epoxy polymer causes the angiosarcomas of the liver and creates asthma-like reactions because of the initiators that are used with epoxy resins. It is evident that there is an utmost need to eliminate epoxy in all aspects of construction activities.

\section{B. Performance of Mineral Admixtures}

Mineral based composites (MBC) involves the replacement of epoxy resin binder by a cementitious mortar containing admixtures like superplasticizers, viscous modifying agents, strengthening additives, etc. It should provide excellent bonding properties, along with good workability, cost efficiency and most importantly compatible with most of the FRP retrofits. The investigation of mechanical behavior performed by [4] for Carbon Fiber Reinforced Composites (CFRC), plain and mineral based composite retrofitted beams to calculate their flexural behavior. As shown in Figure 1 the plain beam showed a brittle failure whereas the fatigue resistance of CFRC and Carbon Fiber Reinforced Polymers (CFRP) retrofitted beams significantly increased. In the end, unlike CFRP retrofitted 
beam, CFRC failed due to rupture of the sheet and not due to delamination.

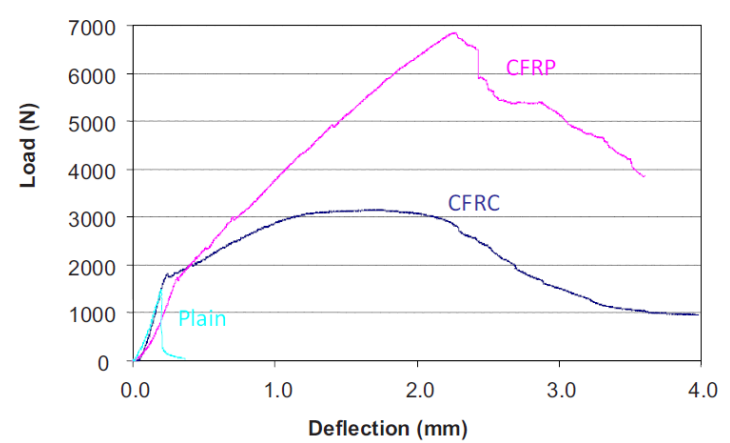

Fig. 1. Flexural response of plain, CFRC and CFRP retrofit Source: Mahal (2013)

[5] studied FRP bond strength in a single-lap (see Figure 2) shear and flexural tests. The bond-slip response identified made it clear that cement-based bonding materials are an effective technique in hot regions or in places where there is a danger of fire. This was because the ultimate load was $80 \%$ greater than CFRP retrofit with epoxy bonding.

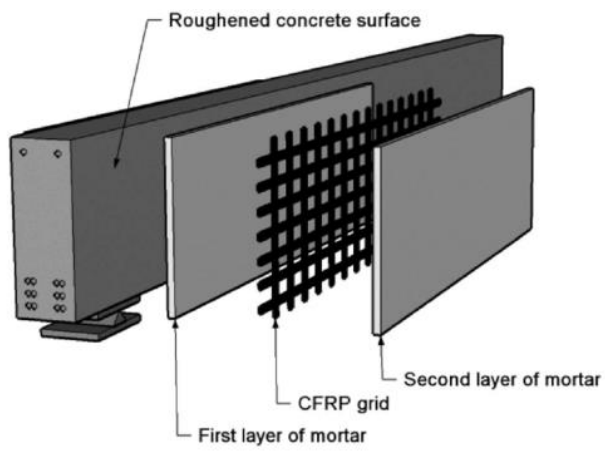

Fig. 2. Overview of Mineral based strengthening system

Source: Hashemi (2010)

\section{Substitute for epoxy resin}

The construction industry and stakeholders have become conscious of the adverse environmental impacts due to construction and started to invest towards green and sustainable techniques. As far as FRP retrofit is concerned, epoxy has been extensively used for the last few decades in damage rectification without the knowledge of its health effects. In the recent years, a considerable amount of research has been put into finding a replacement for epoxy and mineral based cementitious bonders have been gaining popularity in this regard. [6] subjected polymer reinforced powder, epoxy primer and a cement based mortar for shear strengthening of CFRP beams. The modulus of elasticity of the mortars used was $18 \mathrm{GPa}, 26.5 \mathrm{GPa}$ and $35 \mathrm{GPa}$, respectively. LVDTs and strain gauges were used for measuring the displacements and predicted shear capacity was identified as $0.8-1$ times less than the actual shear capacity. The results state that a CFRP grid with smaller tow distance would generate higher load for the first inclined crack. Similarly, the ultimate shear failure load intensifies when CFRP grid in the fiber is upsurged. Blanksvärd et al., (2007) also researched about the consequences of chloride attack and heavy traffic movement to introduce the externally bonded FRP strengthening systems.
FRP strengthened RC beams were subjected to failure for the experimental study involving three different commercially used mortars. As a result, the use of MBC had reduced strains in the steel stirrups and surface cracks. The failure analysis [5] of FRP strengthening system with high temperature using experimental and numerical modelling. As the epoxy adhesion would not be suitable for the environments where the temperature is well below the glass transition temperature (55 $-60^{\circ} \mathrm{C}$ ), mineral-based composites were adopted for testing the bond strength of FRP by a single-lap shear test and the flexural behavior was also subjected to study. The bonding mortar consisted of ordinary Portland cement, micro-cement, water, silica filler, silica fume and superplasticizer (Viscocrete-500). The experimental results are tabulated in Table 1 and from it can be seen that the cement-based bonding materials behave better in high temperature compared to epoxy.

TABLE I. FAILURE OF CFRP SPECIMENS AT HIGH TEMPERATURE
\begin{tabular}{|c|c|c|c|}
\hline Specimen & Bonder & $\begin{array}{c}\text { Temperature } \\
\text { at failure }\left({ }^{\circ} \mathbf{C}\right)\end{array}$ & Failure mode \\
\hline $\begin{array}{c}\text { Control } \\
27 \text { HT beam }\end{array}$ & NA & 876 & Steel yielding \\
\hline $\begin{array}{c}\text { ESF fabric } \\
\text { 38HT beam }\end{array}$ & Epoxy & 462 & Concrete Crushing \\
\hline $\begin{array}{c}\text { MTF textile } \\
38 \text { HT beam }\end{array}$ & Mortar & 850.5 & $\begin{array}{c}\text { FRP debonding and } \\
\text { rupture }\end{array}$ \\
\hline $\begin{array}{c}\text { MTR textile } \\
39 \text { HT beam }\end{array}$ & Mortar & 836.5 & $\begin{array}{c}\text { FRP debonding and } \\
\text { rupture }\end{array}$ \\
\hline
\end{tabular}

\section{TESTING METHODOLOGY}

\section{A. Concrete design and material properties}

A grade 24 concrete is used to prepare the specimens. Both cylindrical $(\Phi 150 \times 300 \mathrm{~mm})$ and cubic $(150 \times 150 \times 150 \mathrm{~mm})$ specimens are cast as per standards. The cement used was Portland Pozzolona cement (PPC) which is manufactured by inter-grinding OPC clinker with $10 \%-25 \%$ of pozzolanic material such as fly ash. The fine aggregate had a fineness modulus of 3.25 and specific gravity of 2.65 . The coarse aggregate consisted of irregularly-sized crushed rock. The maximum size of $20 \mathrm{~mm}$ coarse aggregates with specific gravity 2.63 and fineness modulus 6.78 is used. The water absorption of coarse aggregate is taken as $2.5 \%$ and the volume of entrapped air was considered as $2 \%$ of the concrete mix. The concrete mix proportion is summarized in Table 2 .

\begin{tabular}{|c|c|c|} 
TABLE II. & CONCRETE MIX PROPORTION \\
\hline Materials & Weight $\left(\mathbf{k g} / \mathbf{m}^{\mathbf{3}}\right)$ & Ratio \\
\hline PPC & 502.7 & 1.00 \\
\hline Water & 187.0 & 0.38 \\
\hline Fine Sand & 481.3 & 0.97 \\
\hline 20mm Blue metal & 1173.7 & 2.35 \\
\hline
\end{tabular}

\section{B. Mix proportion of MBC bonder}

The proposed mineral bonder consists of cement, metakaolin (chemical name: Aluminium silicate), VMA, superplasticizer and other admixtures. The cement used was Portland pozzolana cement with specific gravity 3.15 . Metakaolin basically is a supplementary material to be used as strengthening agent and to fill the voids of cement. Viscocrete PC HRF-2 is used as superplasticizer, which is a colorless liquid and a kind of polycarboxylic ether with specific gravity 1.08. This acts as a high range water reducing agent for the cement-based bonder and is compatible with most types of 
cement. Sika VMA is a dark brown colored liquid with specific gravity 1.01, which exhibits superior stability and controlled bleeding characteristics. It is considered as a viscous modifying agent as it controls the rheology of concrete against segregation. Based on available literature and preliminary tests, the following admix proportions are to be used in the innovative bonder.

- Cement

- Metakaolin

$750 \mathrm{~g}$ per cylinder wrapping

- Superplasticizer

$75 \mathrm{~g}$ per wrapping

- VMA $3 \%$ of cement taken 2 drops

It is very important to note that the mineral bonder needs to be viscous enough for easy application at the same time, should not segregate resulting in loss of bonding strength. Therefore, considering the aspects of concrete stability, consistency and safety data sheet provided, the admixtures were chosen from a reputed Australian based company.

\section{Specimen preparation}

A total of 36 cylindrical test specimens are prepared with 18 different specifications as summarized in Table 3. All specimens are prepared and cured at similar conditions to account any loss or variations in their strength. As mentioned below, some of these samples were subjected to partial failure (until initial crack arrives) and full failure (complete loss of strength) before retrofit testing in order to study their bonding performance in every stage.

The cast cylinders are tested for their compressive strength after 28 days of curing. The testing is executed on a universal compression machine at a constant load rate of $20 \mathrm{MPa} / \mathrm{min}$ until failure as per Australian standards AS 1012.8.1: 2014. The modulus of elasticity is found to be $26.6 \mathrm{GPa}$. There are two types of specimen apart from the control specimen; partially damaged specimens (specimen are preloaded by about $70 \%$ of the ultimate load to induce some damage for retrofitting) and fully damaged specimen (specimens are subjected to completely fail before retrofit is carried out).

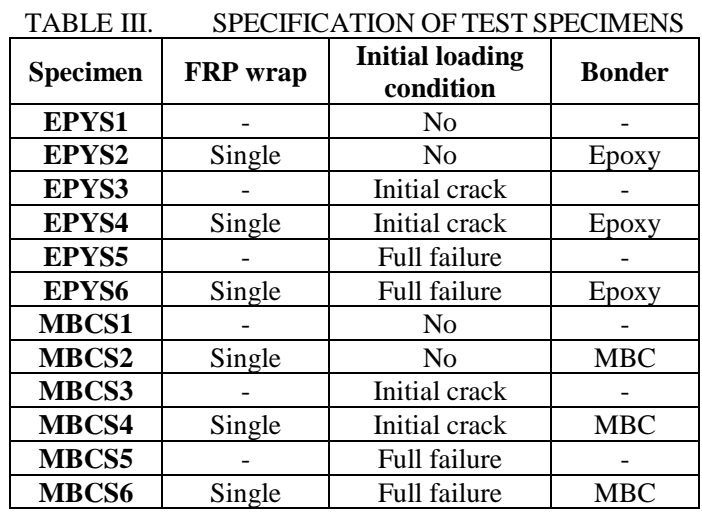

\section{Wrapping of specimens}

After the samples are cast and cured, their outer surface needed to be prepared before application of retrofit. Firstly, the specimen is sun-dried to remove all the moisture in them. Later, the surface is smoothened by grinding or by use of a sandpaper and the loose particles are cleaned out with a brush. One coat of epoxy or MBC bonder is applied to the surface and the bi-directional fiber was wrapped tightly. E-glass fiber is known for its woven roving, the resin-reinforcement ratio rule is $1: 1$ by weight. Glass Fiber sheet is used here because of its compatibility with most of the resins and ideal for multilayer solutions. The specimens with epoxy and $\mathrm{MBC}$ bonder are shown in Figure 3.

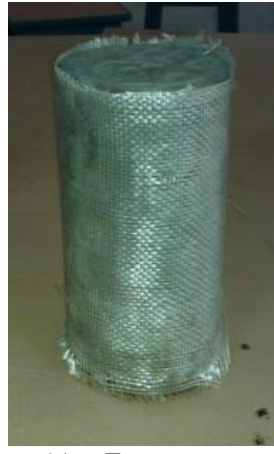

(a) Epoxy

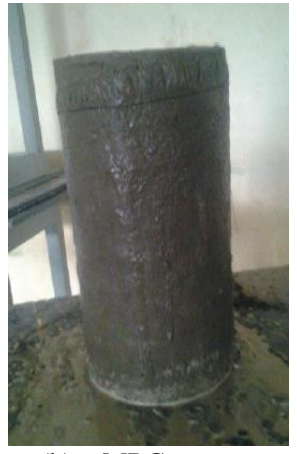

(b) $\mathrm{MBC}$
Fig. 3. GFRP wrapped specimen with epoxy and MBC bonders

All retrofitted specimens are subjected to single wrap retrofit. The wrapping had an overlap of $75 \mathrm{~mm}$ to avoid failure in the overlap region. Then, the second layer of bonder coating is applied to the FRP surface to seal it properly and the setup is cured for 7 days

\section{RESULTS AND DISCUSSION}

\section{A. FRP retrofit using epoxy}

For each type of specimens, three tests are carried out for achieving accuracy in results. The compressive and tensile strengths of the specimens retrofitted with epoxy are tabulated in Table 4.

TABLE IV. RESULTS OBTAINED DURING EPOXY RETROFIT
\begin{tabular}{|c|c|c|c|c|}
\hline \multirow{2}{*}{ Description } & \multicolumn{2}{c}{$\begin{array}{c}\text { Compressive } \\
\text { strength (MPa) }\end{array}$} & $\begin{array}{c}\text { Tensile strength } \\
\text { (MPa) }\end{array}$ \\
\cline { 2 - 5 } & $G F R P$ & CFRP & $G F R P$ & $C F R P$ \\
\hline EPYS1 & 24.4 & 45.1 & 4.35 & 5.20 \\
\hline EPYS2 & 40.3 & 66.4 & 4.86 & 7.28 \\
\hline EPYS3 & 19.2 & 30.3 & 3.08 & 4.50 \\
\hline EPYS4 & 28.8 & 57.7 & 3.97 & 6.31 \\
\hline EPYS5 & 24.4 & 43.3 & 2.10 & 2.10 \\
\hline EPYS6 & 26.5 & 33.9 & 2.98 & 4.54 \\
\hline
\end{tabular}

The comparisons of the strength measured on the specimens with and without wrapping are made for all types of specimens and the increase in strength due to GFRP and CFRP retrofits are found to be substantially high.

\section{B. FRP retrofit using $M B C$}

The same set of compressive and tensile tests are performed for the samples retrofitted with mineral based bonding admixture and the readings are tabulated in Table 5.

TABLE V. RESULTS OBTAINED DURING MBC RETROFIT

\begin{tabular}{|c|c|c|c|c|}
\hline \multirow{2}{*}{ Description } & \multicolumn{2}{|c|}{$\begin{array}{c}\text { Compressive } \\
\text { strength (MPa) }\end{array}$} & \multicolumn{2}{c|}{$\begin{array}{c}\text { Tensile strength } \\
\text { (MPa) }\end{array}$} \\
\cline { 2 - 5 } & $G F R P$ & CFRP & $G F R P$ & CFRP \\
\hline MBCS1 & 23.9 & 45.1 & 4.27 & 5.20 \\
\hline MBCS2 & 36.6 & 59.9 & 4.45 & 6.87 \\
\hline MBCS3 & 18.4 & 30.1 & 3.12 & 4.50 \\
\hline MBCS4 & 28.5 & 53.8 & 3.89 & 6.53 \\
\hline MBCS5 & 23.9 & 46.4 & 2.03 & 2.10 \\
\hline MBCS6 & 26.9 & 36.1 & 3.28 & 6.42 \\
\hline
\end{tabular}

From the comparison of the results, it can be seen that the strength increase with epoxy and MBC is very similar. This 
suggests that the cement-based bonder can be a potentially suitable replacement option for epoxy.

A stress-strain plot is also obtained for GFRP under compressive loading condition is shown in Figure 4. This plot also verifies that the behavior is very similar in both epoxy and $\mathrm{MBC}$ retrofitted samples with pre-existing damage.

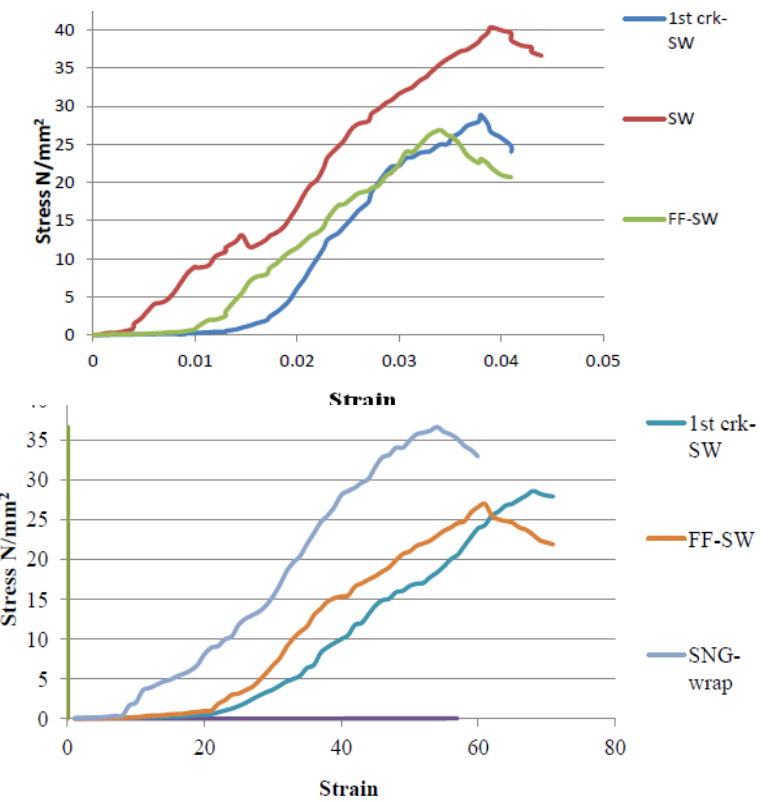

Fig. 4. Stress-strain plots for GFRP single wrap epoxy and MBC specimens

The values obtained establishes the fact that, though epoxy bonding may perform better at initial damage levels, the tensile bonding pursuance seem to be of the highest order for fully failed MBC retrofit. Except for the fully failed epoxy samples, wherein similar tensile strength is attained, the other values differ quite remarkably between both retrofits. Likewise, it can be concluded that CFRP retrofit has improved the bonding robustness for the same bonding admixture when compared to that of E-glass fiber. Similarly, a double wrap retrofit can be introduced if further strength is required. It should also be noted that mineral-based bonder can restrict further damage as it acts as a crack filler and a natural adhesive to RC structural elements.

\section{Comparison of epoxy and MBC performance}

If the results from both epoxy and mineral composite bonders are subjected to comparison, it can be verified that MBC retrofit performs effectively if there is any sort of damage to the concrete member. Table 6 represents the average variation of bonding strength obtained in both cases of retrofit.

TABLE VI. COMPARISON OF STRENGTH INCREASE IN CFRP AND GFRP

\begin{tabular}{|c|c|c|c|c|c|}
\hline \multirow{2}{*}{$\begin{array}{c}\text { Retrofit } \\
\text { Type }\end{array}$} & $\begin{array}{c}\text { Initial } \\
\text { Damage } \\
\text { level (\%) }\end{array}$ & \multicolumn{2}{|c|}{$\begin{array}{c}\text { Compressive strength } \\
\text { increase (\%) }\end{array}$} & \multicolumn{2}{|c|}{$\begin{array}{c}\text { Tensile strength } \\
\text { increase (\%) }\end{array}$} \\
\cline { 3 - 6 } & Epoxy & $M B C$ & Epoxy & $M B C$ \\
\hline \multirow{3}{*}{ GFRP } & Nil & 65.1 & 53.3 & 11.7 & 6.3 \\
\cline { 2 - 6 } & $70 \%$ & 48.8 & 55.5 & 28.9 & 24.7 \\
\cline { 2 - 6 } & $100 \%$ & 8.4 & 12.9 & 41.9 & 61.6 \\
\hline \multirow{3}{*}{ CFRP } & Nil & 47.5 & 32.9 & 40.0 & 32.1 \\
\cline { 2 - 6 } & $70 \%$ & 90.4 & 78.6 & 40.2 & 45.1 \\
\cline { 2 - 6 } & $100 \%$ & 69.5 & 80.3 & 116.2 & 205.7 \\
\hline
\end{tabular}

From the results, it is confirmed that mineral bonders perform well ahead of epoxy resin during partial and complete damage. Though the initial installation of epoxy retrofit may be significant in case of control specimen without any induced damage, it might not be practical as a retrofit is usually preferred only in cases of concrete damage. To normalize the sample populations, the standard errors values are analyzed and results are summarized in Table 7.

TABLE VII. STANDARD ERROR VALUES COMPARISON
\begin{tabular}{|c|c|c|c|}
\hline \multirow{2}{*}{ Specimen } & \multirow{2}{*}{ Damage level } & \multicolumn{2}{|c|}{ Standard error } \\
\cline { 2 - 4 } & & $E P Y$ & $M B C$ \\
\hline \multirow{3}{*}{ CFRP } & Nil & 0.899 & 1.705 \\
\cline { 2 - 4 } & $70 \%$ & 0.660 & 4.745 \\
\cline { 2 - 4 } & $100 \%$ & 0.831 & 3.190 \\
\hline \multirow{3}{*}{ GFRP } & Nil & 0.552 & 2.219 \\
\cline { 2 - 4 } & $70 \%$ & 0.983 & 2.628 \\
\cline { 2 - 4 } & $100 \%$ & 0.949 & 1.148 \\
\hline
\end{tabular}

From Table 7 it can be seen that the epoxy exhibited lower standard error compare with MBC samples. That means epoxy results are more consistent compared with MBC. This variability also can be seen in other cement-based materials From the above data, it is also distinctive that GFRP retrofit has a relatively greater range of accuracy with both bonding agents compare to CFRP. Therefore, it can be noted that both FRP sheets can improve their bonding capacity when the level of damage increases in the structural member and MBC admixture is more suitable with CFRP than GFRP because of its mechanical properties. The increase in compressive strength for both types of FRP specimens at various damage levels is illustrated in Figure 5. It is proven that the graph always progresses in case of CFRP whereas higher damage levels can lead to catastrophic failure in case of glass fibre.

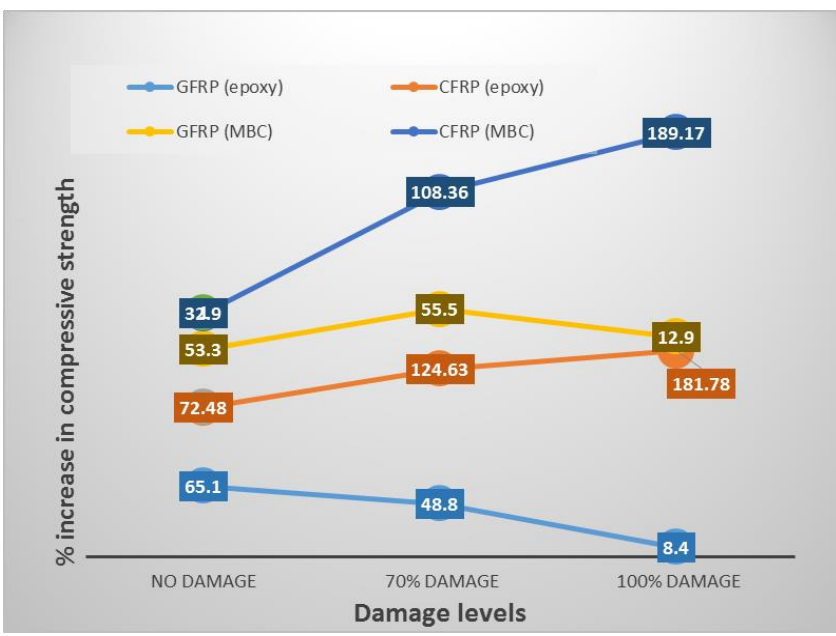

Fig. 5. Epoxy vs. MBC strength increase during compression testing

Moreover, it is verified that CFRP dominates in performance over damaged specimen whereas GFRP is more suitable for a new specimen. Overall, it is suggested that mineral composites act as a better replacement as their characteristic strength has up surged up to 1.5 times in contrast to epoxy during a full failure condition. 


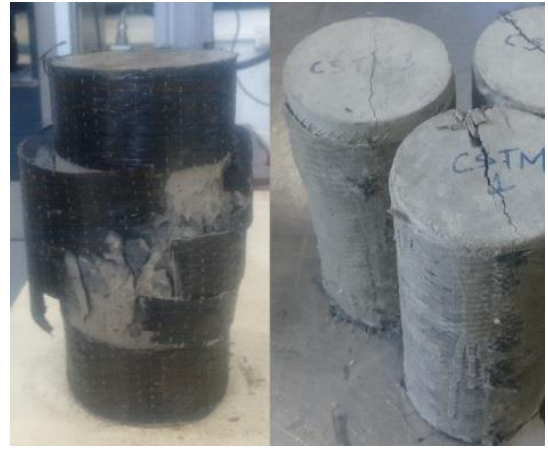

Fig. 6. Failure mode of single wrapped full failure CFRP specimens

In order to understand the failure type of the retrofits the failed specimens are shown in Figure 6. From the figure, it can be seen that the epoxy retrofitted samples failed due to rupture in the middle while delamination occurred in MBC retrofit samples along the previous failure path. However, the strength increase is very similar, except a slight increase in MBC retrofitted samples. This suggests $\mathrm{MBC}$ can be a suitable replacement for epoxy with further investigation to improve the bonding property.

\section{CONCLUSIONS BASED ON RESEARCH OUTCOMES}

The extensive literature study backed by experimental results for the effectiveness of the proposed mineral bonding mix results driven the following outcomes.

- The bonding behavior of FRP strengthened specimens using both epoxy and MBC have very similar behavior in most of the cases

- $\mathrm{MBC}$ retrofit showed up to $15 \%$ superiority in compressive strength for single wrap GFRP compare to epoxy. Whereas, on the other hand, CFRP retains similar behavior and bonding characteristics to that of GFRP retrofit except for around 200\% increase in fully damaged tensile MBC retrofit as presented in Figure 7.

Compressive strength comparison of $\mathrm{MBC}$ retrofitted e-glass and carbon fibres

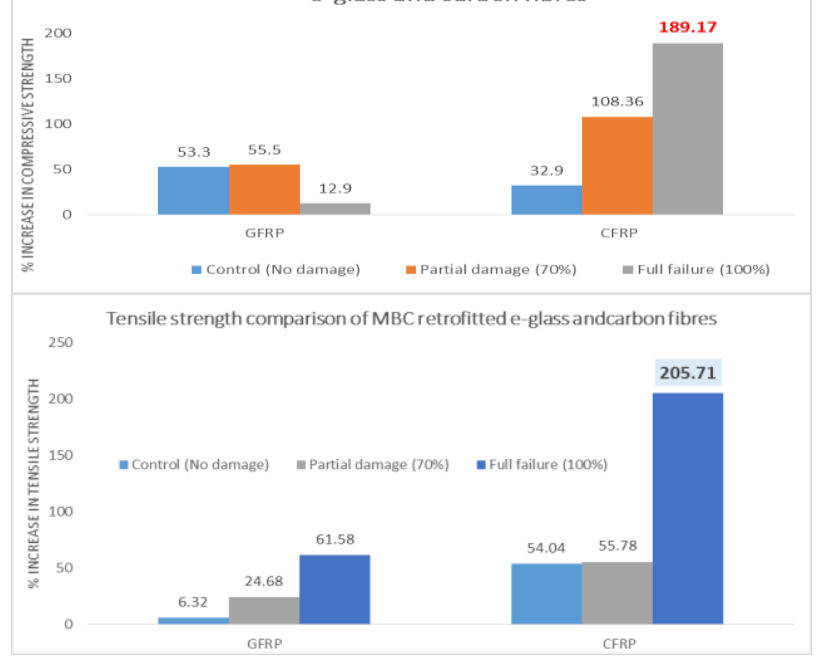

Fig. 7. Mechanical behaviour of MBC retrofitted FRP specimens
- In both types of FRP retrofit, epoxy seems to function better in new specimens or specimens with damage due to its particle size and viscosity. MBC is found to perform better under extreme weather conditions as well as higher levels of damage. Easy availability of the basic materials and admixtures make MBC costefficient and help in achieving a higher degree of sustainability.

- Furthermore, with respect to the compressive and tensile efficiency observations recorded, it can be justified that MBC bonder suitability is greatly oriented towards CFRP retrofit.

Laboratory tests were performed for cylinders with circumferential wrapping. However, this application may not possible in every structural retrofit works due to the limitation in the accessibility of all faces. Further investigation may help to explore the full potential of the MBC bonder in the FRP retrofit that can help in reducing the health concerns associated with the epoxy.

\section{REFERENCES}

[1] Lithner, D., Larsson, A. \& Dave, G.: Environmental and health hazard ranking and assessment of plastic polymers based on chemical composition. Science of the Total Environment 409(18): 3309-3324, 2011.

[2] Prodi, A., Rui, F., Fortina, A.B., Corradin, M.T. \& Filon, F.L. Occupational sensitization to epoxy resins in Northeastern Italy (19962010). International Journal of Occupational \& Environmental Health 21(1): 82, 2015.

[3] Eckardt, R. E.: Occupational and Environmental Health Hazards in the Plastics Industry, National Institute of Environmental Health Sciences. National Institutes of Health. Department of Health, Education and Welfare: 103, 1976.

[4] Mahal, M., Blanksvärd, T. \& Täljsten, B.: Examination at a Material and Structural Level of the Fatigue Life of Beams Strengthened with Mineral or Epoxy Bonded FRPs: The State of the Art. Advances in Structural Engineering 16(7): 1311-1328, 2013.

[5] Hashemi, S. \& R. Al-Mahaidi: Experimental and finite element analysis of flexural behavior of FRP-strengthened RC beams using cement-based adhesives. Construction and Building Materials 26: 268273, 2012.

[6] Blanksvärd, T., Täljsten, B. \& Carolin, A.: Shear Strengthening of Concrete Structures with the Use of Mineral-Based Composites. Journal of Composites for Construction 13(1): 25-34, 2009.

[7] Taljsten, B. \& Blanksvard, T., Mineral-Based Bonding of Carbon FRP to Strengthen Concrete Structures, Journal of Composites for Construction, 11, 120-128, 2007. 